\title{
Analysis of the Means of Combating Birds that Destroy Cereal Crops in the Fields of the Inner Niger Delta
}

\section{Ibrahima Yattara (Corresponding Author)}

Faculty of Sciences and Techniques, University of Sciences, Techniques and Technologies of Bamako, Mali, West Africa

Email: ibrahima_yatt@yahoo.fr

\section{Yacouba Maïga}

Faculty of Sciences and Techniques, University of Sciences, Techniques and Technologies of Bamako, Mali, West Africa

\section{Boubacar Kola Touré}

Faculty of Sciences and Techniques, University of Sciences, Techniques and Technologies of Bamako, Mali, West Africa

\section{Sékou Sacko}

Faculty of Sciences and Techniques, University of Sciences, Techniques and Technologies of Bamako, Mali, West Africa

\section{Mohamed S. Maïga}

Faculty of Sciences and Techniques, University of Sciences, Techniques and Technologies of Bamako, Mali, West Africa
Article History

Received: 12 February, 2021

Revised: 21 March, 2021

Accepted: 10 April, 2021

Published: 15 April, 2021

Copyright (C) 2021 ARPG \&

Author

This work is licensed under the Creative Commons Attribution International

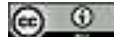

CC BY: Creative Commons Attribution License 4.0

\begin{abstract}
Cereal crops such as rice, millet and sorghum in the Inner Niger Delta are the main sources of food for the people who live there. However, there is a real competition between the high concentrations of grain-eating birds in search of food and the peasants who develop means to preserve their food against these crop destroyers. Rural communities have fought against grain-eating birds and have striven to hunt birds by cutting down trees, destroying nests which only drive them away from neighbors who in turn resume the fight [1]. Various lethal techniques were applied in dozens of countries on all continents during the 1950s [2]. The objective of this study is to know the means of preserving cereal crops by farmers in order to be able to improve agricultural production. For this, several methods are used by the peasants and also by the state. The article discusses the analysis of the different means of control used by farmers and the State against birds destroying cereal crops in the Inner Niger Delta area in Mali, such as traditional methods and chemical methods.

Keywords: Birds; Destroyers; Cereal crops; Means of control.
\end{abstract}

\section{Introduction}

The Inner Niger Delta or DIN has been recognized as a Ramsar site since February 1, 2004. It is so important for people practicing agriculture, fishing, and breeding as well as the animals that live there because of the diversity and the richness of its ecosystem. The primary sector (agriculture, livestock, fishing) is the primary source of economic growth and employs over $80 \%$ of the population. High concentrations of birds, some of which are residents, and others seasonal or migratory, have habitats very suitable for their feeding and reproduction. F. Duhart et la. 1963 presented an inventory of DIN avifauna composed of several species including residents and migrants. Among the bird species, the granivores present in the area constitute real dangers for cereal crops. Thus, the peasants tirelessly engage in the means of struggle against them.

In Mali, Africa and the rest of the world, attacks by seed-eating birds are enormous. Studies by Mallamaire et al, 1961, have shown that since ancient times the destruction of cereal crops by grain-eating birds has been considered one of the major plagues in Africa. Among the most dangerous of these pests are the Quelea quelea who are brazen plunderers of the food grain crops. This is how [3] found that the Quelea-quelea eats an average of 10 grams of seeds per day (about half of its weight) which means that a colony of two million can devour up to 20 tons of seeds. In just one day. These birds attack millet, as well as rice, maize, sorghum and others, the seeds of which they devour when they have reached maturity and even seeds that are still in the milky stage.

According to Guedon [4], the damage caused by bird species by the significant increase in the numbers of their populations are very varied, they mainly relate to the economic sector (damage caused to agricultural or forestry production, to stored foodstuffs, feed). Other studies by Beintema, et al. [5], have shown that crop pest birds are very abundant and very active on the fields and the various habitats of the delta. 


\section{Study Environment}

The Inner Niger Delta is a natural region of Mali that stretches over 64,000 $\mathrm{km}^{2}$, between 4th and 6th degrees West and 13th and 16th degrees North, between the cities of Macina, Djenné and Timbuktu. It is an intermediate part of the course of the Niger, where the river subdivides into many branches before resuming a normal course. The Inner Niger Delta or DIN has been recognized as a Ramsar site since February 1, 2004. It is so important for people practicing agriculture, fishing, and breeding as well as the animals that live there because of the diversity and the richness of its ecosystem.

Despite the existence of several substances in this area used as food for grain-eating birds (bourgou seeds, wild rice, etc.), agricultural production experiences considerable variations in yield depending on the degree of damage caused by the birds. So when birds eat the seeds that humans cultivate, competition is created and if the losses are significant, we would speak of bird species causing crop damage. Farmers in the Inner Niger Delta area have a long tradition of fighting grain-eating birds that destroy cereal crops.

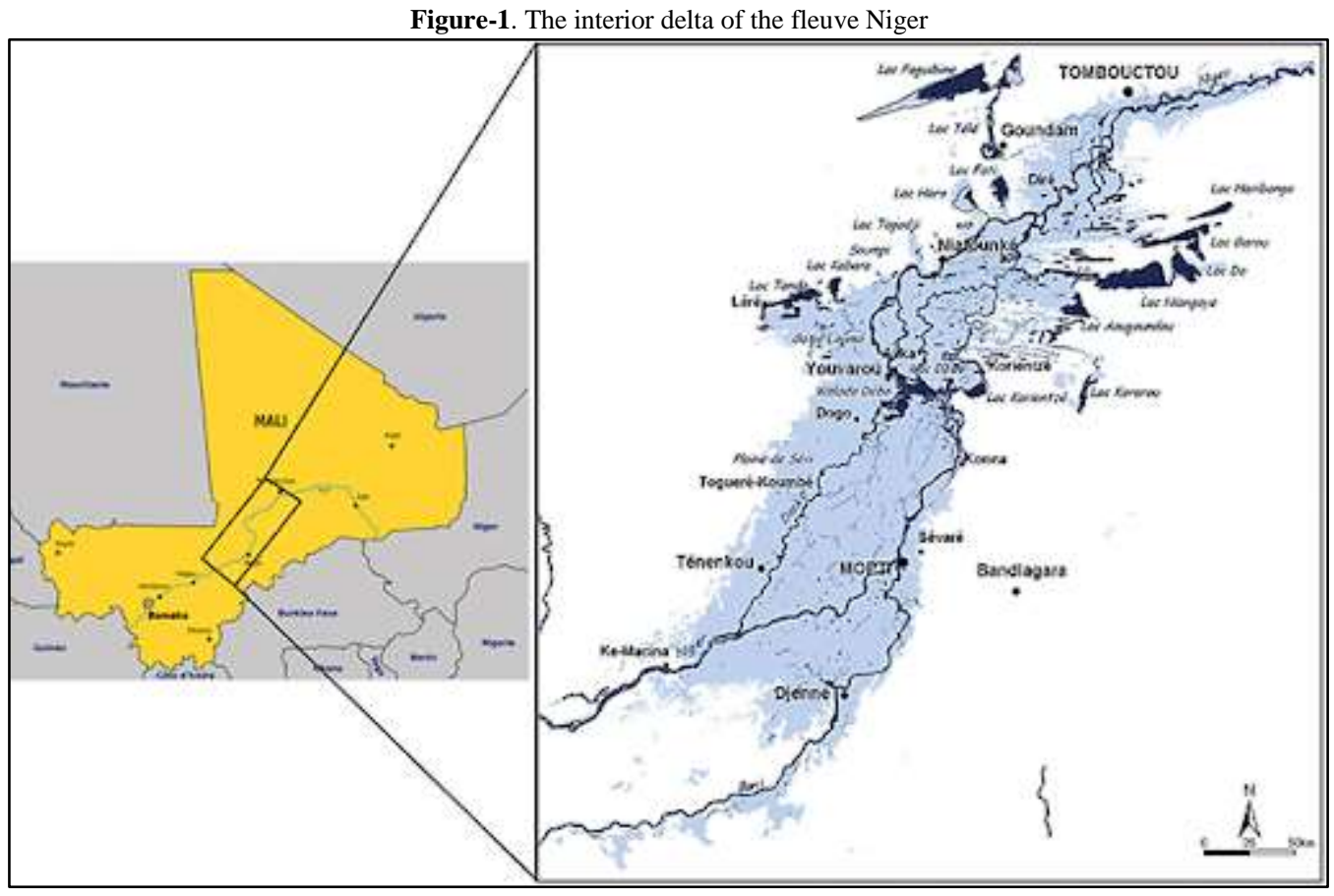

\section{Material and Methods}

\subsection{Material}

Within the framework of the present study, the fields of rice, millet and sorghum were covered on foot or by motorbike in the dry zones and with pinnace in the flooded parts. For the means of combating grain-eating birds that destroy cereal crops, a questionnaire was submitted to the peasants and to the agents of the Agriculture department. The bibliographic review served as a basis for improving this article.

\subsection{Methods of Protecting Peasants}

\subsubsection{Traditional Methods}

The methods of protecting peasants have a long tradition and are generally known and shared by all. The method which consists in chasing the birds of the fields is especially the most frequent. For this purpose the peasants keep the fields from the milky phase until maturation and harvest. For that they have the following means: noise, projectiles, cords to draw, gunshots, scarecrows. These control methods are used in the various crop fields (millet, rice, sorghum). Other traditional protection methods are also used by farmers such as destroying nests with fire or sticks, pruning trees around fields, etc.

In many cases, these means of struggle are used without any prior study. This can cause considerable ecological damage. Guarding is a very widespread practice in Africa, time-consuming and having negative repercussions especially on the schedule of peasant families but, unfortunately, always irreplaceable at the farmer level. Its performance must be improved by rationalizing the behavior of the guardian and by adding other direct protection techniques. These different methods used are most degrading factors for the environment. Consequently, new forms of crop protection must be considered by the technical services of agriculture. Growing sorghum cultivars having awns, large glumes and inverted heads can contribute in reducing losses caused by the birds especially when here is plenty of food around [6].

\subsubsection{Chemical Means}

For the preservation and improvement of agricultural production, the State uses various and effective means for the fight against grain-eating birds, in particular: 
- The spraying of pesticides by air (use of airplanes): over the course of several years the use of avicide spraying has been imposed by the specialized State services (General Directorate of the Office of Plant Protection). Birds must be in contact with the product especially in areas with high concentrations (nesting areas, roosts) where birds stay together the longest.

- Traditional agricultural spraying which uses products such as penthion (spray) in the fields. This technique is only successful if the distribution of the product remains uniform on the ground and on the vegetation. This technique is only successful if the product distribution remains uniform on the ground and on the vegetation.

\section{Results and Discussion}

The control strategies used by the peasants are determined according to certain times of the day and the places of their gathering or in the fields of cultivation. Generally, the specialized services of the State intensify the chemical treatment during the return of the evening when the birds have a great flight activity and are eager to group in their dormitories or nesting areas or in the morning of happiness when they leave. For foraging the bird's contact with the drops may be by sedimentation or by impact. During contact by sedimentation, the bird receives only the drops of the product which are deposited on it when it falls. The quantity of drops is limited. On impact contact, the bird flies through the product and accumulates as it goes. This presents more harm than sedimentation. In a rapid and severe poisoning, the bird falls and, shortly after, dies.

By terrestrial devices: this technique consists in using atomizers from the ground especially for small surfaces. The atomizer produces a very fine spray liquid. Spraying takes place from a fixed point with one or more devices. All the avian place must not be covered, one or more strips of the product are sufficient for the passage of birds. This experience was developed by GTZ in Niger in the fight against birds [7]. The multiplication of other ecosystems abounding in abundance with wild seeds and water and the traditional methods of control commonly used by the peasants should help to save crops in the fields of small areas which are located in the vicinity of the villages and hamlets of cultures [8]. The Inner Niger Delta area is very large and includes several areas of cultivable land. The protection of cereal crops with traditional methods is not very effective because of the very abundant numbers of species of grain-eating birds that destroy crops (Quelea quelea, Passer luteus, Ploceus cuculatus, etc.) present in the environments. Thus, each year despite the granting of a good rainfall, the peasants worry about the damage that can cause birds destroying cereal crops as indicated by Köning [9] for the Quelea quelea species living in immense bands in contact human and capable of causing enormous damage to cereal crops.

As part of the precautions to be taken, the General Directorate of the Plant Protection Office (OPV) disseminates information and awareness messages for the populations of the areas affected by aerial chemical treatments for the precautions to be taken. And what to do before, during and after spraying with avicides. In Mali, two main types of control methods are used against birds [10]: direct methods which act on populations of birds which have started to cause damage, or which are likely to do so soon (guarding, installation of scaring devices ...) and indirect methods to reduce the attractiveness of fields and the care given to the crop. But in the case of direct methods installed as a preventive measure, the need to protect all crops before the damage begins only allows the use of relatively inexpensive methods.

To this end, Mali is one of the 34 African countries regularly hit by the Quelea quelea plague and other granivorous species such as Ploceus cuculatus, Passer luteus, etc. The damage caused by grain-eating birds is often appreciable and the species are almost always polyphagous according to N'Doye [11], for whom the reduction of these ravages was of concern to the Joint Organization for the Control of Locusts and Bird Control. (OCLALAV) which has been the subject of several projects In its perspectives, the management of the OPV, recommends a better knowledge of the phenomenon to determine an appropriate strategy of fight in order to initiate a framework of subregional cooperation for a concerted fight.

\section{Conclusion}

The means of combating birds that destroy cereal crops in the rice, millet and sorghum fields of the Inner Niger Delta are the traditional methods used by the peasants, the spraying of pesticides by air (use of planes) used by the state and the use of pesticides by some farmers.

\section{References}

[1] Ruelle, P. and Bruggers, R. L., 1982. "Traditional approaches for protecting cereal crops from birds." In Proceedings of the Tenth Vertebrate Pest Conference.

[2] Mallamaire, L. and Wilson, A., 1961. "Control of grain-eating birds in West Africa (Senegal, Mauritania, Sudan, Niger)." Journal of Tropical Agriculture and Applied Botany, vol. 8, pp. 248-265.

[3] Elliot, C., 2009. The quelea, Africa's most feared bird. IRIN. FAO. Johannesburg. News at the heart of crises.

[4] Guedon, G., 1997. "Birds at risk in towns and in the countryside towards integrated population management? ." In National Institute of Agronomic Research 147, rue de l'université 75338 Paris Cedex 07.

[5] Beintema, A. J., Fofana, B., and Diallo, M., 2001. "Management of flooded forests in the Inner Niger Delta, Mali, Altérra-report 341. Wetlands International, Sevaré / Alterra, Green World Research, Wageningen Netherlands." 
[6] Shiringani, L. A., 2005. Evaluation of hard endosperm, bird-proof sorghum [Sorghum bicolor L. (Moench) and its effect on food quality. MSc Thesis. Bloemfontein. South Africa: University of the Free State.

[7] Dorow, E., 1991. "Bird control. Experiments carried out in the Republic of Niger / MAG / EL-DPV / Plant protection project. GTZ."

[8] Manikowski, S., N'Diaye, A. B., and Treca, B., 1991. Manual of crop protection against bird damage, Dakar. FAO.

[9] Köning, C., 2013. Pests for our cereals, P, 24-04-2013 and modified on 24-10_2016. File classified under Botany, Medicine, Cereals. Futura-Sciences.

[10] Treca, B., 1985. The possibilities of controlling water birds to protect rice fields. Bamako, Republic of Mali: ORSTOM mission BP 2528.

[11] N'Doye, M., 1979. New pests of millet in Senegal and the Sahelian zone. Rome, Italy: FAO, Plant Production and Protection Div. 